\title{
SARS-COV2 Alters Blood Brain Barrier Integrity Contributing to Neuro-Inflammation
}

\author{
Jessica. L. Reynolds ${ }^{1} \cdot$ Supriya D. Mahajan ${ }^{1}$ \\ Received: 24 November 2020 / Accepted: 2 December 2020 / Published online: 6 January 2021 \\ (C) The Author(s), under exclusive licence to Springer Science+Business Media, LLC part of Springer Nature 2021
}

To the Editor,

Emerging clinical data suggests that $\sim 40 \%$ of COVID-19 patients develop neurological symptoms attributed to viral encephalitis, resulting in neuro-inflammation, neuronal damage and severe hypoxia (Wu et al. 2020; Najjar et al. 2020; Muccioli et al. 2020; Mao et al. 2020). SARS-COV-2 infects the host using the widely expressed angiotensin converting enzyme 2 (ACE2) receptor (Bourgonje et al. 2020), however, no there are no reports on ACE2 receptor expression by human brain microvascular endothelial cells (BMVEC) and normal human astrocytes (NHA) which constitute the Blood Brain Barrier (BBB). We posit that SARS-CoV-2 enters the central nervous system (CNS) via ACE2 receptors present on BMVEC and NHA, alters tight junction (TJ) proteins leading to disruption in BBB integrity which leads to neuro-invasion of microglia. Overall, SARS-COV-2 exacerbates neuro-inflammation, increases oxidative stress and consequently contributes to neuronal cell death.

Expression of ACE2 Receptor by hBMVEC Primary hBMVEC (Cat\# ACBRI-376; Cell Systems, Kirkland, WA, USA) basal expression levels of ACE2 receptor and SARS-COV-2 induced expression was examined by immunofluorescence staining using an ACE2 receptor primary antibody (1:1000 dilution; Cat\# NR-52481, BEI Resources Inc) followed by staining with an Alexa Fluor 647 labelled secondary antimouse antibody (1:2000, Cat \#A 28181; ThermoFisher Scientific) and nuclear stain DAPI. Receptor expression was measured using an EVOS ${ }^{\circledR}$ FL Cell Imaging System, Invitrogen, and quantitated using ImageJ software. Figure 1a

Supriya D. Mahajan

smahajan@buffalo.edu

1 Department of Medicine, Division of Allergy, Immunology \& Rheumatology, Jacobs School of Medicine and Biomedical Sciences, Clinical \& Translational Research Center, University at Buffalo, 875 Ellicott Street, Buffalo, NY 14203, USA shows basal ACE2 receptor expression in BMVEC which was significantly increased following SARS-COV-2 spike protein treatment. We are the first to report that primary human BMVEC express ACE2 receptor which is increased by SARS-COV-2 spike protein exposure.

SARS-COV- 2 Affects BBB Integrity A well validated in-vitro 2D BBB co-culture system trans-well model that closely mimics and accurately reflects in vivo characteristics and functional properties was used (Mahajan et al. 2008; Reynolds and Mahajan 2020). Trans-endothelial electrical resistance (TEER) across the in vitro BBB was measured using an ohm meter Millicell ERS system (Millipore, Bedford, MA Cat \# MERS 000 01). To determine the effect of SARS-COV2 on BBB integrity, we treated the BBB with recombinant SARS-COV-2 spike protein $(0.5 \mu \mathrm{g} / \mathrm{ml})$ and/or heat inactivated SARS-COV-2 ( $5 \mu \mathrm{l} / \mathrm{ml}$ media), for $24 \mathrm{~h}$ followed by TEER measurement across the BBB. Figure $1 \mathrm{~b}$ shows a significant decrease in TEER in BBB treated with SARSCOV2 spike protein $(29 \%$ decrease; $p<0.05)$ and/or heat inactivated SAR-COV $2(30 \%$ decrease; $p<0.05)$ treatment as compared to the untreated control. These data suggesting that exposure to SARS-COV-2 alters BBB integrity thus enabling neuro-invasion.

Effect of SARS -COV-2 on Tight Junction Modulation The properties of the BBB are primarily determined by junctional complexes between the cerebral endothelial cells, comprised of tight, adherens and gap junctions which when disrupted leads to increased BBB permeability particularly through the paracellular route (Luissint et al. 2012). Human BMVEC were treated with recombinant SARS-COV-2 spike protein or heat inactivated SARS-COV-2 spike protein for $24 \mathrm{~h}$., followed by RNA extraction from BMVECs using the TriZol Method followed by reverse transcription. Real time quantitative PCR (Q-PCR) was used to evaluate Tight Junction proteins (TJP's) ZO-1, ZO-2, Claudin- 5 and junction adhesion molecule 2 (JAM-2) gene expression. The relative abundance of each mRNA species was 
a

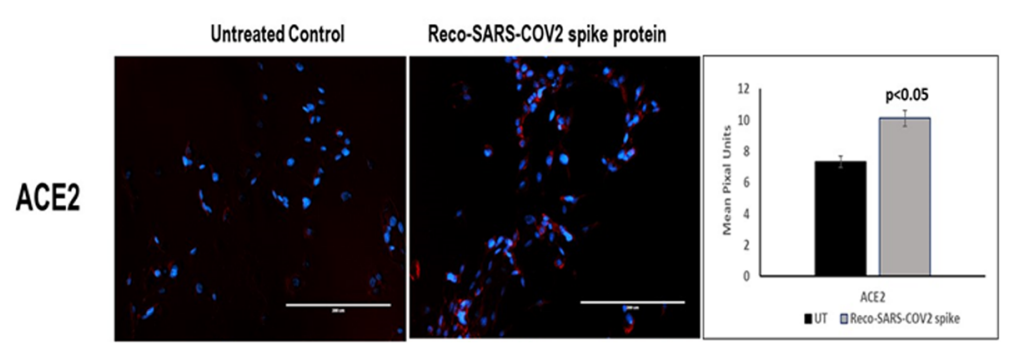

b

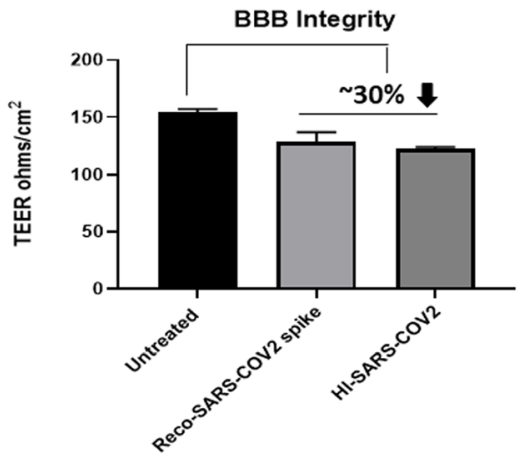

C

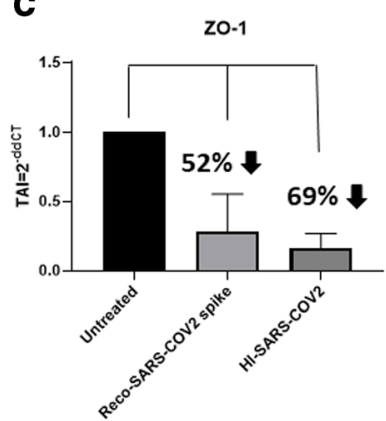

d

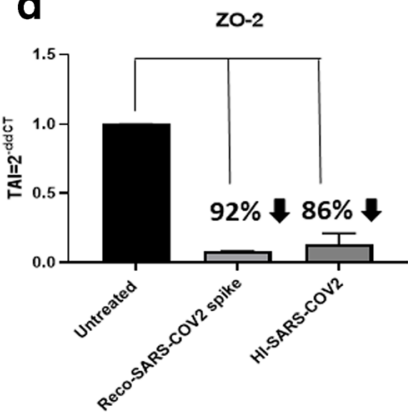

Fig. 1 Our experimental paradigm included treating primary human BMVEC (Cat\# ACBRI-376) with $5 \mu \mathrm{l}(0.5 \mu \mathrm{g} / \mathrm{ml})$ media $(0.1 \mu \mathrm{g} / \mu \mathrm{l}$ stock) recombinant Spike protein from SARS-Related Coronavirus 2, Wuhan-Hu-1 (Cat \# NR-52308; Lot: 70034410 BEI resources Inc) or $5 \mu 1$ of Heat Inactivated SARS-Coronavirus 2, Isolate USA-WA1/2020, (Cat \# NR-52286, Lot: 70033548; Pre-Inactivation Titer by TCID50

quantitated by normalizing the expression levels of each mRNA to the endogenous $\beta$-actin levels. Q-PCR was done using validated specific primers and the Brilliant SYBR green Q-PCR master mix (Stratagene Inc., La Jolla, CA). All samples and controls were run in triplicate on a Stratagene MX3000P realtime PCR system. Relative expression of mRNA species was calculated using the comparative threshold cycle number $\left(C_{\mathrm{T}}\right)$ method and expressed as Transcript Accumulation Index $(\mathrm{TAI})=2^{-\Delta \Delta C}$, assuming that all PCR reactions are working with $>95 \%$ efficiency (Schmittgen and Livak 2008). We observed a significant decrease in the gene expression levels of TJPs ZO-1 (52\%; $p<0.05)$, ZO-2 (92\%; $p<0.001)$, Claudin-5 $(97 \% ; \mathrm{p}<0.001)$ and JAM-2 $(45 \% ; \mathrm{p}<0.05)$ in BMVEC treated with recombinant SARS-COV-2 spike protein as compared to the untreated controls. Additionally, we also observed a significant decrease in the gene expression levels of ZO-1 (69\%; $p<0.01)$, ZO-2 (86\%; p < 0.001), Claudin-5 (95\%; p < 0.001) and JAM-2 $(85 \% ; \mathrm{p}<0.001)$ in BMVEC treated with heat inactivated SARS-COV-2 spike protein as compared to the untreated controls. These data suggest that SARS-COV-2 induced changes in TJP gene expression levels and/or post-translational modifications modulate junctional protein function which directly affects BBB integrity and function.

SARS-COV-2 Generates a Cytokine Storm Supernatant from BMVEC cell cultures treated with SARS-CoV-2 spike protein
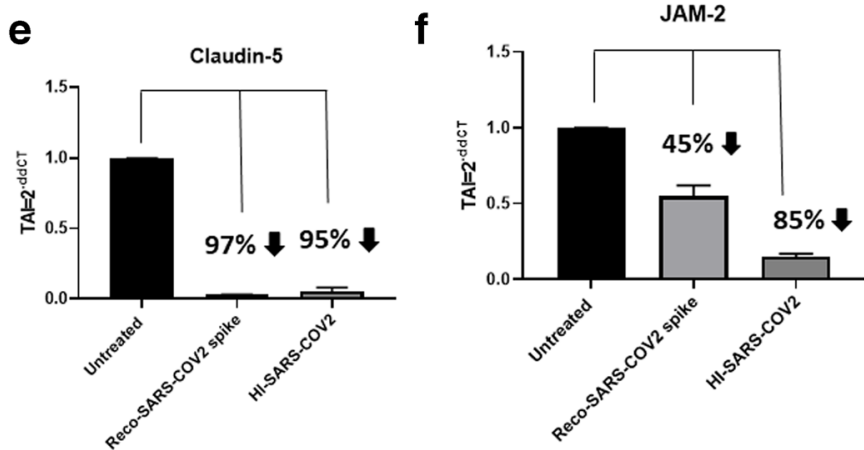

Assay in Vero E6 Cells $=1.6 \times 10^{5}$ TCID50 per mL, BEI resources Inc) for $24-48 \mathrm{~h}$, followed by examining ACE2 receptor expression, BBB integrity, TJ protein gene expression levels and levels of proinflammatory cytokines. a Immunofluorescent staining of ACE-2 receptor on BMVEC; b Measurement of TEER; c-f ZO-1, ZO-2, Claudin-5 and JAM-2 gene expression data as analyzed by QPCR

virus were quantitated for cytokines using BioLegend's LEGENDplex ${ }^{\mathrm{TM}}$ bead-based immunoassay. Table 1 shows the levels of all cytokines measured. Results show a significant increase in TNF- $\alpha(p<0.01)$, IL-6 $(p<0.0001)$, IL-10 $(p<0.05)$, IL-23 $(\mathrm{p}<0.05)$ and IL-33 $(\mathrm{p}<0.01)$ release as compared to the untreated controls, suggesting a significant increase in pro-inflammatory cytokines. Increased levels of pro-inflammatory cytokines IL-6, TNF- $\alpha$, IL-8, IL-10, were reported among fatal COVID-19 cases, suggesting that hypercytokinemia, may underlie neuroinflammation that is typical in COVID -19 associated encephalopathy (Muccioli et al. 2020; Mao et al. 2020).

These data suggests that the SARS-COV-2 viral proteins via the ACE2 receptor on BMVEC cells can induce endothelial inflammation and alter BBB integrity which may facilitate neuro-invasion of SARS-COV-2. SARS-COV-2 may transverse the BBB by spike protein-ACE2 interactions or through nonspecific endocytosis, and this could drive neuroinflammatory responses associated with neuro-pathology. Recent report suggests that SARS-COV-2 may also drive neuro-inflammatory responses in the absence of functional entry into the target cell cytoplasm, as viral degradation in the endosome or lysosome can trigger the activation of pathogen-associated molecular patterns (PAMPs), and / or danger-associated molecular patterns (DAMPs) to that may modulate immune response (Al-Harthi et al. 2020). 
Table 1 Effect of SARS-COV2 treatment on levels of cytokines in BMVEC

\begin{tabular}{lllllllllllll}
\hline Human BMVEC & IL- & INF- & INF- & TNF- & MCP-1 & IL-6 & IL-10 & IL-12 $\mathrm{p} \mathrm{70}$ & IL- & IL-18 & IL-23 & IL-33 \\
& $1 \beta$ & $\alpha 2$ & $\gamma$ & $\alpha$ & & & & & & 17A & & \\
\hline Concentration units & $\mathrm{pg} / \mathrm{ml}$ & $\mathrm{pg} / \mathrm{ml}$ & $\mathrm{pg} / \mathrm{ml}$ & $\mathrm{pg} / \mathrm{ml}$ & $\mathrm{pg} / \mathrm{ml}$ & $\mathrm{pg} / \mathrm{ml}$ & $\mathrm{pg} / \mathrm{ml}$ & $\mathrm{pg} / \mathrm{ml}$ & $\mathrm{pg} / \mathrm{ml}$ & $\mathrm{pg} / \mathrm{ml}$ & $\mathrm{pg} / \mathrm{ml}$ & $\mathrm{pg} / \mathrm{ml}$ \\
UT & 11.98 & 3.61 & 0.84 & 3.15 & 1381.43 & 1622.7 & 7.12 & 4.29 & 0.41 & 5.37 & 2.89 & 26.04 \\
Reco-SARS-COV2 & 10.68 & 2.95 & 0.94 & 8.31 & 1024.64 & $58,880.65$ & 11.15 & 6.29 & 0.69 & 5.44 & 5.83 & 35.61 \\
\hline
\end{tabular}

However, we believe, that SARS-COV-2 associated endothelial cell dysfunction preludes the neuropathology associated with SARS-COV-2 that is observed in COVID-19 infected patients. Thus, anti-cytokine based therapeutics or therapies that prevent $\mathrm{BBB}$ damage may be effective in treating patients with COVID-19 associated neurological disease. Additional studies that investigate molecular mechanisms that underlie SARS- COV-2 associated neuropathology are warranted.

Acknowledgments Research reported in this publication was supported by the National Center for Advancing Translational Sciences of the National Institutes of Health under award \#'s KL2TR001413 (JR); UL1TR001412 (JR) to the University at Buffalo, R01AI129649- (JR) and 1R01DA047410 (SM). The content is solely the responsibility of the authors and does not necessarily represent the official views of the $\mathrm{NIH}$.

Authors wish to acknowledge the receipt of the following reagents through BEI Resources. These reagents were produced under HHSN272201400008C and obtained through BEI Resources, NIAID, NIH and were specifically procured for this study: 1) Spike Glycoprotein (Stabilized) from SARS-Related Coronavirus 2, WuhanHu-1 with C-Terminal Histidine Tag, Recombinant from Baculovirus, (NR-52308); 2) Heat Inactivated SARS- Coronavirus 2, Isolate USAWA1/2020, (NR-52286); 3) Monoclonal Anti-SARS Coronavirus Recombinant Human Antibody, Clone CR3022 (produced in HEK293 Cells) (NR-52481).

\section{References}

Al-Harthi L, Campbell E, Schneider JA, Bennett DA (2020) What HIV in the brain can teach us about SARS-CoV-2. Neurological Complications? AIDS Res Hum Retrovir. https://doi.org/10.1089/ aid.2020.0161

Bourgonje AR, Abdulle AE, Timens W, Hillebrands JL, Navis GJ, Gordijn SJ, Bolling MC, Dijkstra G, Voors AA, Osterhaus AD, van der Voort PH, Mulder DJ, van Goor H (2020) Angiotensinconverting enzyme 2 (ACE2), SARS-CoV-2 and the pathophysiology of coronavirus disease 2019 (COVID-19). J Pathol 251(3):228248

Luissint AC, Artus C, Glacial F, Ganeshamoorthy K, Couraud PO (2012) Tight junctions at the blood brain barrier: physiological architecture and disease-associated dysregulation. Fluids Barriers CNS 9(1):23

Mahajan SD, Aalinkeel R, Sykes DE, Reynolds JL, Bindukumar B, Fernandez SF, Chawda R, Shanahan TC, Schwartz SA (2008) Tight junction regulation by morphine and HIV-1 tat modulates blood-brain barrier permeability. J Clin Immunol 28(5):528-541

Mao L, Jin H, Wang M, Hu Y, Chen S, He Q, Chang J, Hong C, Zhou Y, Wang D, Miao X, Li Y, Hu B (2020) Neurologic manifestations of hospitalized patients with coronavirus disease 2019 in Wuhan, China. JAMA Neurol 77(6):683-690

Muccioli L, Pensato U, Cani I, Guarino M, Cortelli P, Bisulli F (2020) COVID-19-associated encephalopathy and cytokine-mediated Neuroinflammation. Ann Neurol. https://doi.org/10.1002/ana. 25855

Najjar S, Najjar A, Chong DJ, Pramanik BK, Kirsch C, Kuzniecky RI, Pacia SV, Azhar S (2020) Central nervous system complications associated with SARS-CoV-2 infection: integrative concepts of pathophysiology and case reports. J Neuroinflammation 17(1):231

Reynolds JL, Mahajan SD (2020) Transmigration of Tetraspanin 2 (Tspan2) siRNA via microglia derived exosomes across the blood brain barrier modifies the production of immune mediators by microglia cells. J NeuroImmune Pharmacol 15(3):554-563

Schmittgen TD, Livak K (2008) Analyzing real-time PCR data by the comparative $\mathrm{C}(\mathrm{T})$ method. Nat Protoc 3:1101-1108

Wu Y, Xiaolin X, Chen Z, Duan J, Hashimoto K, Yang L, Liu C, Yanga C (2020) Nervous system involvement after infection with COVID19 and other coronaviruses. Brain Behav Immun 87:18-22

Publisher's Note Springer Nature remains neutral with regard to jurisdictional claims in published maps and institutional affiliations. 